\title{
Signs and Symptoms of Tuberous Sclerosis Complex
}

Pogancev $\mathrm{MK}^{1^{*}}$, Tatjana $\mathrm{RM}^{2}$ and Ivana $\mathrm{PS}^{3}$

${ }^{1}$ Child and Youth Health Care Institute of Vojvodina, Novi Sad, Serbia

${ }^{2}$ Department of Developmental Neurology, School of Medicine, University of Novi Sad, Serbia

${ }^{3}$ Department of Developmental Neurology and Epileptology-Pediatritians, School of Medicine, University of Novi Sad, Serbia

*Corresponding author: Marija Knezevic Pogancev, Child and Youth Health Care Institute of Vojvodina, School of Medicine, University of Novi Sad, Serbia, Tel: 381-63-7789285; E-mail: mkp.marija@gmail.com

Received date: Jun 11, 2017; Accepted date: Jun 13, 2017; Published date: Jun 20, 2017

Copyright: (c) 2017 Pogancev MK, et al. This is an open-access article distributed under the terms of the Creative Commons Attribution License, which permits unrestricted use, distribution, and reproduction in any medium, provided the original author and source are credited.

\section{Editorial}

Tuberous Sclerosis Complex (TSC) is a multisystem disorder. Described in 1908 as a VOG tries, including adenoma sebaceum, epilepsy and mental retardation. Because TSC affects no two people in the same way, there is no sure way to predict where and how the disorder will manifest.

57 patients at the Child and Youth Health Care Institute of Vojvodina were diagnosed with TSC on the basis of hypomelanotic skin lesions and epileptic seizures (45.61\%), hypomelanotic skin changes, cardiac rhabdomyomas and epileptic seizures (21.05\%), hypomelanotic skin changes and neuroimaging (3.51\%), epileptic seizures and neuroimaging (10.53\%) and epileptic seizures and kidney changes (1.75\%).

\section{Tuberous Sclerosis Complex Features}

Diagnosis is based on symptoms and signs presentation which are differentiated as major and minor clinical TSC characteristics (Table 1) [1-3].

\begin{tabular}{|l|l|}
\hline Major features of TSC & Minor TSC Features \\
\hline $\begin{array}{l}\text { Facial angiofibromas or forehead } \\
\text { plaque }\end{array}$ & "Confetti" skin lesions \\
\hline Ungual fibroma (>2) & $\begin{array}{l}\text { Multiple randomly distributed dental } \\
\text { enamel pits }(>3)\end{array}$ \\
\hline $\begin{array}{l}\text { Hypomelanotic macules (>3 and }>5 \\
\text { mm) }\end{array}$ & $\begin{array}{l}\text { Radial migration lines in cerebral white } \\
\text { matter }\end{array}$ \\
\hline Shagreen patch & Rectal polyps (hamartomas) \\
\hline Multiple nodular retinal hamartoma & Bone cysts \\
\hline Cortical tuber & Gingival fibromas (>2) \\
\hline Sub ependymal nodules & Nonrenal hamartoma \\
\hline $\begin{array}{l}\text { SEGA tumors (sub ependymal giant } \\
\text { cell astrocytoma) }\end{array}$ & Achromic retinal patch \\
\hline Cardiac rhabdomyoma & Renal cysts (multiple) \\
\hline Lymphangioleiomyomatosis & - \\
\hline Renal AML & - \\
\hline
\end{tabular}

Table 1: Differentiation of major and minor clinical TSC characteristics.

\section{Neurological TSC Features}

Several types of brain c may be seen in patients with TSC, including cortical tubers, Sub Ependymal Nodules (SEN), and SEGA tumors. Some individuals will have all of these changes, whereas others will have none. The vast majority of individuals with TSC, however, will have one of these abnormalities. Abnormal neurological findings result from their location, size, and growth [4-6].

Seizures occur in $60-90 \%$ of children with TSC, in three quarters of infants when they are manifested as epileptic spasms. $57.9 \%$ of children having TSC have the first attack during within first 6 months of life, $75 \%$ within the first year and $6.4 \%$ after the age of five. Multifocal or focal EEG changes are found in over $70 \%$ of patients with TSC. It is believed that the development of epilepsy after the first attack in TSC is $100 \%$.

Mental retardation depends on the presence of epileptic seizures and the development of epileptic encephalopathy, as well as on the secondary damage to the localization of nodules, astrocytoma, or SEGA tumor or it can be a result of hydrocephalus.

\section{Skin changes}

The best recognised TSC cutaneous manifestation are hamathoma: Adenoma sebaceum, angiofibroma. They appear in early childhood and show progression during puberty and adolescence. Other skin lesions presents as: Hypomelanotic macules, ungual and gingival fibromas, shagreen patch or forehead and face patches [7].

\section{Cardiac findings}

Cardiac manifestations of TSC are usually maximal presented at birth and during early in life $(22 / 26 \mathrm{GW})$. Rhabdomyomas are present in $50-60 \%$ of patients with TSC at birth. $50-85 \%$ of infants with isolated cardiac rhabdomyomas at birth will present other signs of TSC during later life. Patients with TSC and atrial or ventricular rhabdomyomas usually do not exhibit any symptoms. There might be signs of cardiac failure, hydrops or even fetal death. Rhabromyomas involving the cardiac conducting system may predispose ventricular pre-excitation or other arrhythmias.

\section{Ophthalmic findings}

Ocular abnormalities are present in $50-80 \%$ of TSC patients. Analogous to hypomelanotic skin macules hypo pigmented areas of retina, iris, and even eyelashes are reported. 


\section{Renal findings}

Renal manifestations are the second most common clinical features of TSC, manifesting as: autosomal dominant polycystic kidney disease, isolated renal cysts, Angiomyolipomas (AML), and renal cell carcinoma [8].

Polycystic kidney disease present in 2-3\% of TSC patients, during early life causing hypertension, hematuria, nephrolithiasis or renal failure. They are present in patients with genetic abnormality affecting TSC2 and PKD1 gene. Usually asymptomatic renal cysts are present in $20 \%$ of male and $10 \%$ of female TSC patients.

AMLs are noted in as many as $80 \%$ of persons with TSC. They also can occur as isolated lesions in persons without TSC. They appear as multiple small AMLs studding the kidney surface of the kidney or as a larger lesion, giving symptoms if they are over $4-6 \mathrm{~cm}$ in their largest diameter. 75\% AMLs over 6-8 cm diameter often cause hemorrhage. Large AML and renal cell carcinoma appear frequent in TSC patients.

\section{Lung findings}

Symptomatic pulmonary involvement are present exclusively in adult women ( $>30$ years), in $40 \%$ as AMLs over $4-6 \mathrm{~cm}$ diameter. They mostly present as: multifocal micronodularpneumocytehyperplasia, pulmonary cysts, and Lymphangioleiomyomatosis (LAM).

\section{Dental findings}

Large number of pitting of the dental enamel is present in permanent teeth of TSC patients. In the primary (deciduous) teeth they are present in $30 \%$ of affected children, rarely producing symptoms. Smaller numbers $(<6)$ of dental pits is present in $10 \%$ of healthy controls. Gingival fibromas occurs in $70 \%$ of adults and $50 \%$ of children with mixed dentition, but only in $3 \%$ of TSC children with only primary teeth. Gingival fibromas associated with more than 10 dental pits are highly suggestive of TSC.

\section{Other organs systems features}

Gaster, intestine, and colon hamartomas and polyposis occur, almost without significant symptoms. Gastrointestinal hamartomas occasionally cause bleeding. Asymptomatic and non-progressive are hepatic cysts and AML are present in $24 \%$ of TSC patients, with, with female-to-male ratio 5:1.

Sclerotic and hypertrophic bone lesions may be found incidentally on radiography, occasionally palpable, or associated with nonspecific, vague, aching pains.

Arterial aneurysms, intracranial, aortal or axillary are very rare.

\section{TAND-TSC associated neuropsychiatric disorders}

Around $90 \%$ of TSC patients have a range of behavioral, psychiatric, intellectual, academic, neuropsychological and psychosocial difficulties. TAND-tuberous sclerosis complex-associated neuropsychiatric disorders bring together these multidimensional manifestations of the disorder [9].

\section{Our Patients}

57 patients at the Child and Youth Health Care Institute of Vojvodina were diagnosed with TSC on the basis of hypomelanotic skin lesions and epileptic seizures (45.61), hypomelanotic skin changes, cardiac rhabdomyomas and epileptic seizures (21.05), hypomelanotic skin changes and neuroimaging (3.51\%), epileptic seizures and neuroimaging $(10.53 \%)$ and epileptic seizures and kidney changes (1.75\%).

\section{Conclusion}

Because TSC affects no two people in the same way, there is no sure way to predict where and how the disorder will manifest, but in children skin changes, seizures and cardiac rhabdomyoma are dominant clinical signs.

\section{References}

1. Borkowska J, Schwartz RA, Kotulska K, Jozwiak S (2011) Tuberous sclerosis complex: tumors and tumorigenesis. Int J Dermatol 50: 13-20.

2. Atay AE, Akbas H, Sakar N, Pasa S, Ari S, et al. (2013) Clinical manifestations of tuberous sclerosis complex. East J Med 18: 52-59.

3. Shan H, Dao-Yu H, Wen-Zhen Z, Liang W, Zi W (2016) Tuberous sclerosis complex: Imaging characteristics in 11 cases and review of the literature. J Huazhong Univ Sci Technolog Med Sci 36: 601-606.

4. Katz JS, Frankel H, Ma T, Zagzag D, Liechty B, et al. (2017) Unique findings of subependymal giant cell astrocytoma within cortical tubers in patients with tuberous sclerosis complex: a histopathological evaluation. Childs Nerv Syst 33: 601-607.

5. Neerja P (2016) A study on clinical manifestations of tuberous sclerosis. J Pak Assoc Derm 23: 365-370.

6. Arthur R, Leroy V, Riquet A, Gogneaux L, Boutry N, et al. (2016) Renal involvement in tuberous sclerosis complex with emphasis on cystic lesions. La Radiologia Medica 121: 402-408.

7. Curatolo P, Moavero R, Vries PJ (2015) Neurological and neuropsychiatric aspects of tuberous sclerosis complex. Lancet 14: 733-745.

8. Leclezio L, Jansen A, Whittemore VH, de Vries PJ (2015) Pilot validation of the tuberous sclerosis-associated neuropsychiatric disorders (TAND) checklist. Pediatr Neurol 52: 16-24.

9. De Vries PJ, Whittemore VH, Leclezio L, Byars AW, Dunn D, et al. (2015) Tuberous sclerosis associated neuropsychiatric disorders (TAND) and the TAND Checklist. Pedia Neurol 52: 25-35. 